\title{
Parametric analysis of energy harvesting pavements operated by air convection
}

\author{
A. Chiarelli*, A.R. Dawson, A. García \\ Nottingham Transportation Engineering Centre (NTEC), Faculty of Engineering, The \\ University of Nottingham, University Park, Nottingham, NG7 2RD
}

\begin{abstract}
In this paper, an energy harvesting pavement prototype using air as the operating fluid is described and analyzed. The prototype harvests the thermal energy available in the pavement through pipes embedded in its structure, where air flows thanks to natural convection. The air is able to exit the system through an updraft chimney. A parametric analysis of the controllable parameters of interest is performed in this work in order to evaluate the variation in the performance of the energy harvesting prototype in different experimental setups. This study shows that there exists a maximum value for the air speed in each configuration and that the energy harvesting efficiency depends on the height and the diameter of the chimney. Moreover, there is a minimum value of the chimney diameter that does not allow air movement and makes the whole system behave as if no pipes were embedded in the pavement structure.
\end{abstract}

Keywords: air, energy harvesting, asphalt pavement, optimization, solar energy

\section{1. Introduction}

2 Since pavements are always exposed to environmental factors, their sur3 face temperature is widely influenced by them. During the summer months,

\footnotetext{
* Corresponding author

Email addresses: chiarelli.andrea@gmail.com (A. Chiarelli), andrew.dawson@nottingham.ac.uk (A.R. Dawson), alvaro.garcia@nottingham.ac.uk (A. García)

Preprint submitted to Applied Energy

June 6, 2015
} 
4 the surface temperature may be around $70^{\circ} \mathrm{C}$ in daytime [1, i.e. substantially higher than ambient. This high temperature is responsible for a number of common damages to roads. In particular, the rate of change of the temperature is identified as the main responsible of asphalt thermal cracking [2, while high temperatures alone are implicated in premature asphalt rutting.

A high surface temperature suggests that thermal energy is accumulated in the pavement structure, thus, it is possible to design systems that are able to collect this energy [1] [3]. Energy harvesting pavements are commercially available in the form of solar collectors, i.e. sets of pipes embedded in the pavement structure in order to host an operating fluid that extracts the energy there accumulated.

In [3], Bobes-Jesus et al. present a detailed state-of-the-art review on asphalt solar collectors and provide guidance on the parameters that most influence the energy harvesting process in pavements. The use of energy harvesting pavements is shown and analysed in various recent studies, such as [3], 4], and [5]. The use of asphalt as a collector, nonetheless, is of older origins, and its applications range from snow-melting systems [6] to the heating of buildings [7] or pools $[\underline{8}$. The analyses found in the literature were performed with either theoretical methods [7] [5] or with the use of finite element models [9]. Furthermore, the experimental studies carried out in previous works allowed the comparison of the laboratory results with various theoretical models [4] [5].

According to [3], however, all the energy harvesting pavement systems currently in use are based on water as the operating fluid. This implementation has an important flaw, because in the case of system failures leakages may have a negative impact on the pavement durability [4]. Furthermore, the installation of liquid-filled pipes below the wearing course implies the need to use these technologies only in low trafficked areas, as concerns may arise about the mechanical resistance of this kind of pavement, especially in the case of a leakage.

32 For these reasons, in 4. García and Partl show a new implementation of en-

33 ergy harvesting pavements, switching from the widespread use of water as the ${ }_{34}$ operating fluid to the use of air, which has no negative effect on the pavement 
structure in the case of leakages. The system described in 4] consists of a set of pipes embedded in an asphalt slab and used to allow air to flow through a chimney used as the system outlet thanks to natural convection, thus, also avoiding the need of machinery to power the fluid flow.

The conclusions of the few previous investigations on air powered energy harvesting asphalt pavements suggest that this technology may be seen as a viable alternative to currently available systems [4] [5]. Its study, however, is at a very early stage, therefore new steps need to be made to discover which parameters most influence its design. García and Partl were able to prove the feasibility of the technology 4, but no extended analysis was performed and only a correlation between the height of the chimney and the mass flow rate was reported.

This study is meant to represent a new step in the understanding of air powered energy harvesting systems, as it consists of a parametric analysis carried out to identify the most significant parameters in the design of this recently developed kind of energy harvesting systems. The objective of the tests performed was the analysis of the behaviour of the energy harvesting efficiency with different experimental setups. The gathered data was interpreted to assess whether it is possible to generate an air flow of given velocity and/or to reduce effectively the surface temperature of the pavement. Finally, another objective was to find out if this technology is able to generate an air flow that is fast enough to drive a small air turbine for electricity production. The results gathered can provide guidance for further investigations and for the design of new, larger prototypes for field tests.

\section{Experimental setup}

The energy harvesting prototype shown in Fig. 1 was designed and built at the Nottingham Transportation Engineering Centre (NTEC) to mimic a real pavement, thus, it consists of two layers: the top layer is made of a dense asphalt mixture (limestone aggregate, maximum size $11 \mathrm{~mm}$ and bitumen 40/50 pen, thickness $5 \mathrm{~cm}$ ), while the bottom layer is compacted limestone gravel (11 
$\mathrm{mm}$, thickness $13.5 \mathrm{~cm}$ ). Both layers were placed in a wooden box, which is thermally insulated with a $2.5 \mathrm{~cm}$-thick layer of extruded polystyrene foam on all sides except for the surface.

A set of 13 perforated stainless steel pipes were buried in the aggregate layer. The vertical pipe spacing is $5 \mathrm{~cm}$, while the horizontal spacing is $10 \mathrm{~cm}$. The spacing between the pipes was chosen based on a layout that could be easily produced in our laboratory, therefore, further studies on this need to be performed.

On the side of the air inlet, the pipes are open to the surrounding air, while on the other side there is an air volume in what is called an air box. An elbow connector is connected to the air box to allow the use of an updraft chimney to drive the air flow outside the system. The characteristics of the chimney (diameter and height) were changed to perform the parametric analysis.

No device is needed to move the air through the pavement, as its motion is based on natural convection only.

Tools and instruments. The pavement was meant to simulate the energy withdrawal from a hot pavement, thus, incandescent gas-filled infrared light bulbs were used to heat the asphalt surface.

The temperatures in the pavement domain were logged with an OMEGA OMBDAQ-54 acquisition device interfaced with the software Personal DaqView. The datalogger was connected to five Type $J$ thermocouples that were placed in the positions marked as "T" in Fig. 2 .

The air speed at the outlet was measured with a PCE-423 anemometer.

The workstation (computer and acquisition devices) was protected with a slab of extruded polystyrene foam, so that the electronic equipment would not suffer from the high temperature of the light bulbs.

\section{Tests performed}

Since the pipes are buried in the pavement layers, the investigation focused on the effect of the chimney and the volume of air in the system on the final 


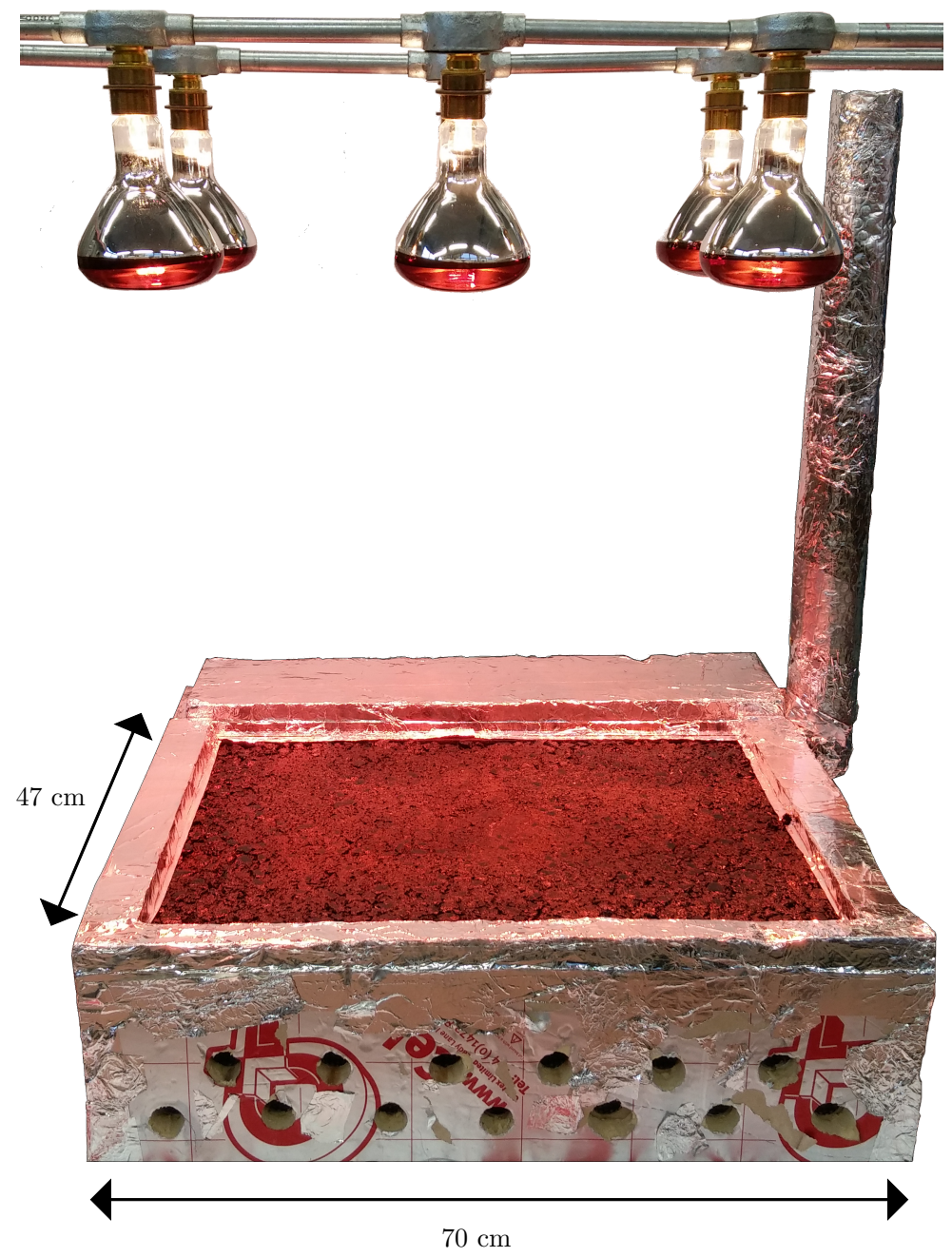

Figure 1: Prototype in the laboratory.

${ }_{93}$ performance in terms of air speed and maximum temperatures in the domain.

94 The main parametric analysis that was carried out involved the use of a chimney of different length and diameter, namely:

- $65 \mathrm{~mm}$ internal diameter, height from 0.25 to $2.5 \mathrm{~m}$

- $40 \mathrm{~mm}$ internal diameter, height from 0.25 to $2.5 \mathrm{~m}$

98

- $32 \mathrm{~mm}$ internal diameter, height from 0.25 to $2.5 \mathrm{~m}$ 


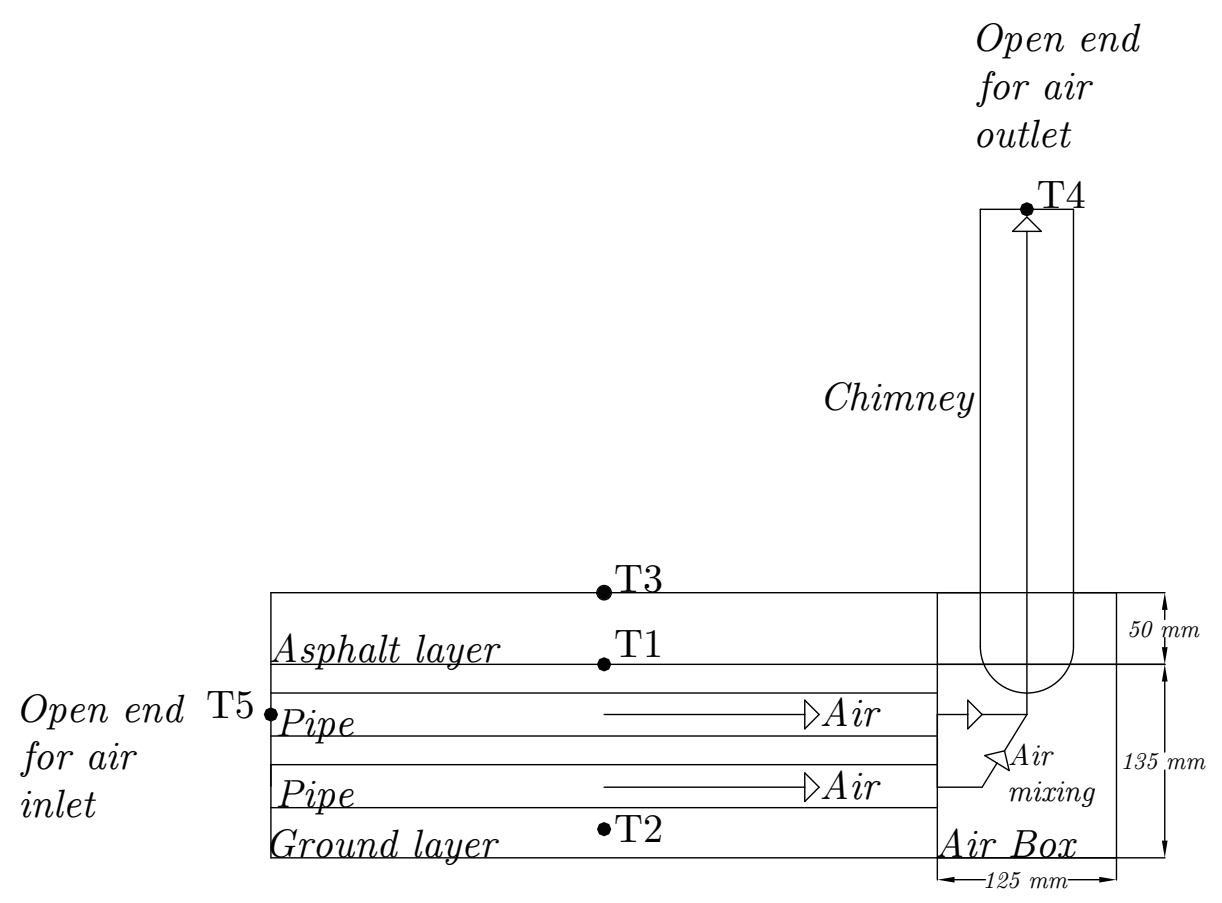

Figure 2: Position of the Type $\mathrm{J}$ thermocouples in the experimental setup, adapted from [5].

- $20 \mathrm{~mm}$ internal diameter, height from 0.25 to $2.5 \mathrm{~m}$

Moreover, additional tests were performed in order to evaluate the influence of the volume of the air box and of the total volume of air in the buried pipes on the performance of the system. The volume of the air box was reduced by partially filling it with insulation material (extruded polystyrene foam), while the influence of the volume of air in the pipes was analysed by blocking different sets of pipes, thus, preventing air from flowing through them.

\section{Results and discussion}

\subsection{Temperatures in the domain}

The values of temperature in the domain were monitored through a data logger and processed. As an example, the behaviour of the temperatures of interest in a complete test is shown in Fig. 3 (1 m long chimney, $65 \mathrm{~mm}$ diameter). This complete test consists of a heating phase of 24 hours and a cooling 

between, approximately, hour 15 and hour 24 .

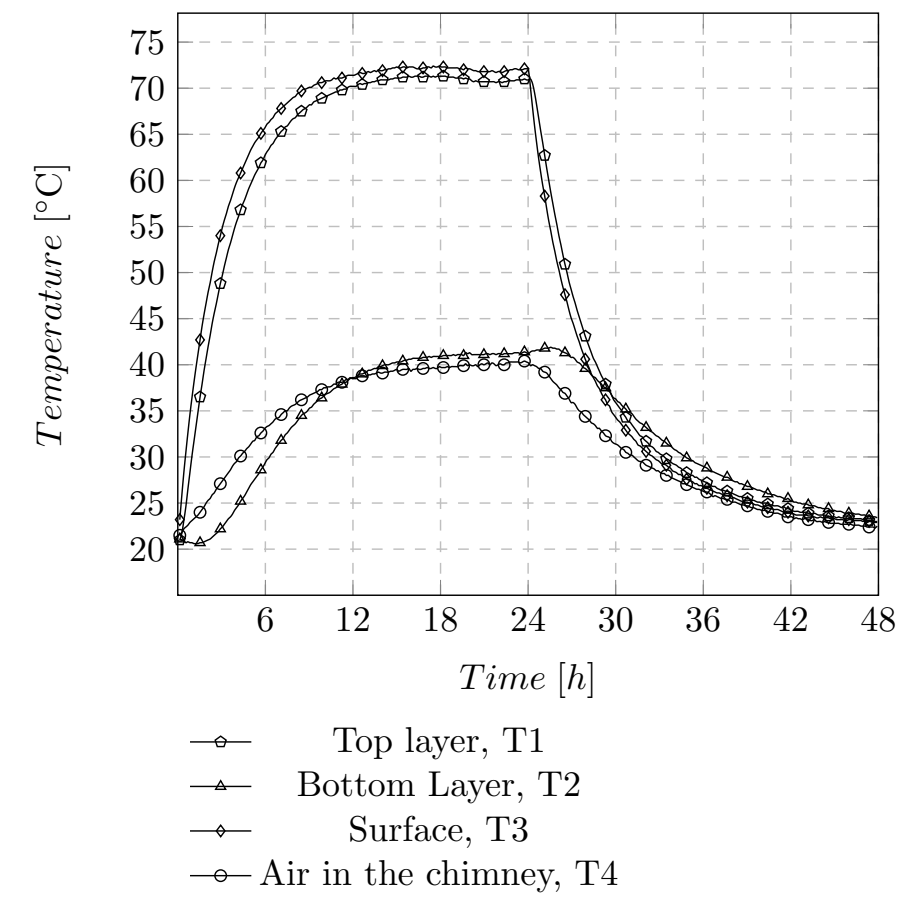

Figure 3: Behaviour of temperatures in a complete test.

down phase of 24 hours. The duration of the tests was chosen in order to always reach a steady-state condition, which can be identified in Fig. 3 as the plateau

As shown in Fig. 4. the temperatures of the asphalt surface and of the air at the chimney outlet have an apparently erratic behaviour, as there does not seem to be any clear link between them. In fact, the measured temperatures show a different behaviour for every diameter that was considered. The values that were obtained from the tests performed are gathered together in Appendix A In the case of a chimney diameter of $20 \mathrm{~mm}$, no air flow was measured for heights $>1.5 \mathrm{~m}$, thus, implying that the heat convection mechanism does not work in those configurations. For this reason, the results of the tests with taller chimneys of diameter of $20 \mathrm{~mm}$ are not shown in Fig. 4

${ }_{124}$ The only conclusion that can be drawn from the simple analysis of the temperatures shown in Appendix $\mathrm{A}$ is that the measured values are consistent, as the 


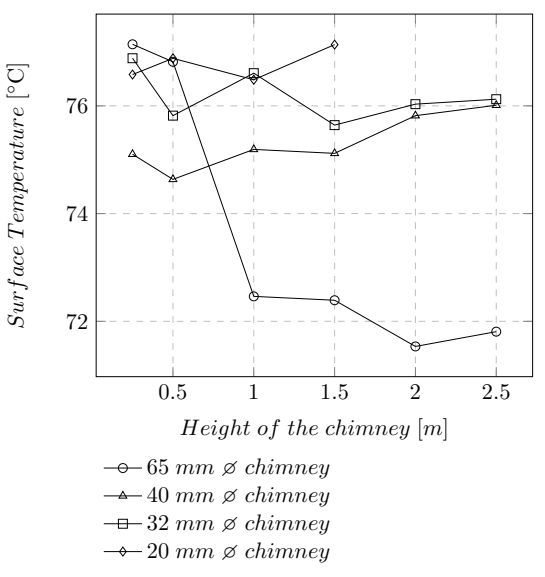

(a) Surface Temperature

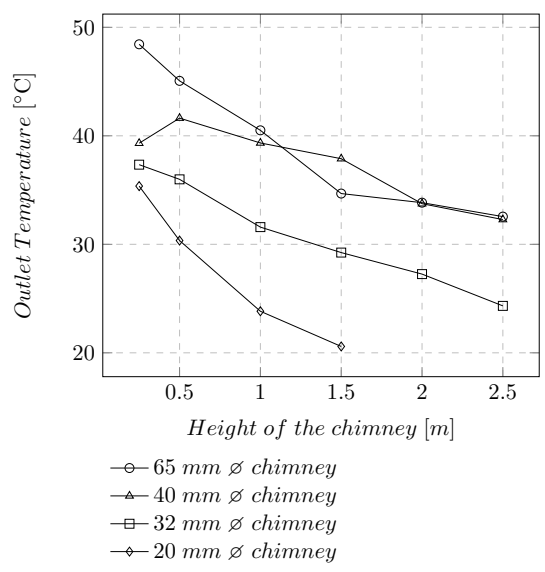

(b) Outlet Temperature

Figure 4: Temperatures in the domain with changes in the chimney diameter and height.

temperature in the asphalt layers is decreasing with depth. The temperature in the chimney, however, does not show a behaviour that can be explained solely from simple thermodynamic considerations. In fact, if only thermodynamics was influencing the system, the temperature in the chimney would always be a bit lower than the temperature of the aggregate layer (which is linearly related to the surface temperature through Fourier's law of thermal conduction) and behave in a similar way, while this was not observed in the tests performed.

\subsection{Relationship between air speed and temperature}

As shown in Fig. 5 the measured values of air speed at the chimney outlet peak at different chimney heights. The calculation of the Reynolds number $(R e)$ was performed to determine whether the shape of the curves was influenced by the flow regime or not. In fact, for $R e$ below 2040, the fluid regime is considered to be laminar, while for values above 2040 the flow is turbulent [10. The values of $R e$ were calculated as:

$$
R e=\rho \cdot v \cdot D_{h} / \mu
$$

where $\rho$ is the density of air in the chimney, $v$ is the air speed, $D_{h}$ is the internal diameter of the chimney, and $\mu$ is the dynamic viscosity of air. The density of air 


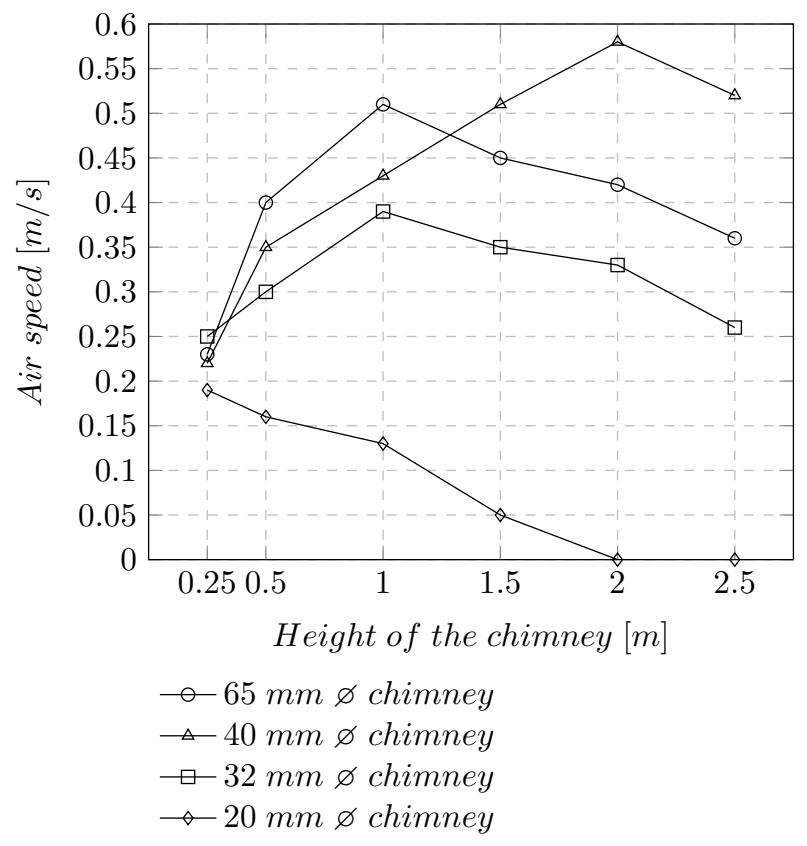

Figure 5: Measured air speed in the parametric analysis.

can be calculated based on the ideal gas law under the assumption that at the outlet the air pressure is equal to the atmospheric pressure. This is not strictly true, as the prototype works by creating a depression related to a difference in the air density. However, the depression is so small that, for the purpose of calculating the value of $R e$, this approximation can be accepted. Moreover, in order to perform a valid comparison, it is important to consider the variations in the dynamic viscosity of air with changes in the air temperature and density. This can be done using the Sutherland's equation, i.e.,

$$
\mu=\mu_{r e f} \cdot\left(\frac{T}{T_{r e f}}\right)^{3 / 2} \cdot \frac{T_{r e f}+S}{T+S}
$$

where $\mu_{r e f}$ is the reference dynamic viscosity for air, $1.716 \mathrm{E}-5 \mathrm{~kg} / \mathrm{ms}, T$ is the temperature of air in the chimney, $T_{r e f}$ is equal to $273.15 \mathrm{~K}$, and $S$ is Sutherland's constant, which in the case of air is equal to $110.4 \mathrm{~K}$.

Therefore, the Reynolds number can be computed for all the tests that were performed: the results gathered in Table 1 show that the Reynolds number goes 


\begin{tabular}{l|llll} 
Chimney & \multicolumn{4}{|c}{ Chimney diameter } \\
Height & $65 \mathrm{~mm}$ & $40 \mathrm{~mm}$ & $32 \mathrm{~mm}$ & $20 \mathrm{~mm}$ \\
\hline $0.25 \mathrm{~m}$ & 830.99 & 836.49 & 1005.70 & 738.96 \\
$0.50 \mathrm{~m}$ & 1472.44 & 1313.43 & 1208.51 & 640.74 \\
$1.00 \mathrm{~m}$ & 1926.08 & 1634.72 & 1592.64 & 541.17 \\
$1.50 \mathrm{~m}$ & 1757.13 & 1954.96 & 1438.65 & 212.27 \\
$2.00 \mathrm{~m}$ & 1647.99 & 2277.05 & 1343.54 & $\mathrm{n} / \mathrm{a}$ \\
$2.50 \mathrm{~m}$ & 1423.14 & 2058.93 & 1069.29 & $\mathrm{n} / \mathrm{a}$
\end{tabular}

Table 1: Reynolds number, Re, for the tests performed.

over the turbulence threshold in two cases, and it is maximim in the case of highest air speed $(\varnothing 40 \mathrm{~mm}$, height $2 \mathrm{~m})$.

This means that in order to obtain a high speed in the outlet of the prototype the designer should focus on engineering a configuration that allows the air flow to reach turbulence rather than considering the variation of the temperatures in the domain. This can be done by choosing a more appropriate diameter for the chimney and by optimizing the height of the outlet. Moreover, the effect of the air box could be studied in detail to evaluate its influence on the performance of the systems.

Furthermore, it is interesting to analyse in detail the curves shown in Fig. 5 as they seem to have an irregular behaviour. Generally speaking, with the use of smaller chimneys the head losses due to friction are expected to increase, thus, the speed is supposed to be lower. This is what happens for chimney heights of $0.5 \mathrm{~m}$ and $1 \mathrm{~m}$, however, this phenomenon is not reported for higher chimneys. In fact, for chimney heights larger than $1 \mathrm{~m}$, the air speed recorded for the largest chimney becomes lower than the one recorded for a chimney diameter of $40 \mathrm{~mm}$. The reason for this is that the prototype described in this paper is small-sized, thus, when the volume of air inside the chimney increases, the heat harvested from the pavement might not be enough to generate density differences between inlet and outlet that are higher than in the other configurations. This phenomenon is temperature-driven, as lower temperatures imply lower densities (and consequently lower air velocities). The confirmation 
of these principles is found in Appendix A, where the chimney temperature is reported for all the tests performed.

Finally, it is worth mentioning that as a general rule a higher air speed inside the pavement can be related to an increase of the convective heat transfer coefficient, thus, the energy harvesting potential in such conditions should increase.

\subsection{Generation of energy}

As shown in Fig. 5, with the prototype used it was not possible to generate an air speed high enough to drive a small air turbine, because the instantaneous cutin speed is generally higher than at least $2 \mathrm{~m} / \mathrm{s}$ for standard air powered systems 11. Furthermore, since the available literature on turbines of the necessary size is not extensive, it is not possible to evaluate clearly the feasibility of electricity generation at this point. However, the very small size of the asphalt surface in the prototype relative to the diameter of the chimney is probably the limiting factor, since a larger area feeding a chimney would provide a higher volumetric air flow and, consequently, a higher air speed.

This technology also allows the use of the heat extracted from the pavement, even if the air has a low temperature. In fact, there exists the potential of employing heat pumps to use the harvested heat to produce domestic hot water, which would in turn reduce the energy consumption of buildings. The fact that the temperature of the air is relatively low is not an issue in this kind of application, as the use of low-enthalpy heat in heat pumps is an established technology [12] 13].

Finally, it is relevant to mention that all uses of this technology would allow a reduction of the urban heat island effect [14] [15, as the pavement surface temperature reduction is achieved in all cases. 


\subsection{Efficiency of the prototype}

The efficiency of the prototype can be estimated using a definition based on energy [5], i.e.,

$$
\eta=\frac{\dot{m} \cdot c_{p, c} \cdot\left(T_{c}-T_{e}\right)}{q_{\max }}
$$

where $\dot{m}$ is the mass flow of air in the chimney, $c_{p, c}$ is the specific heat capacity, $T_{c}$ is the temperature of air at the outlet (chimney), $T_{e}$ is the temperature of the environment, and $q_{\max }$ is the maximum heat flux available for harvesting. The value of $q_{\max }$ is calculated as

$$
q_{\max }=q_{a}-q_{w a}-q_{c a}
$$

where $q_{a}$ is the total heat flux available in the pavement, $q_{w a}$ is the heat lost by radiation, and $q_{c a}$ is the heat exchanged by convection with the ambient air by the pavement surface [4]. The values of $q_{w a}$ and $q_{c a}$ can be computed as:

$$
\left\{\begin{array}{l}
q_{w a}=\sigma \cdot A_{a} \cdot \varepsilon_{a} \cdot\left(T_{e}^{4}-T_{a}^{4}\right) \\
q_{c a}=h_{a} \cdot A_{a} \cdot\left(T_{e}-T_{a}\right)
\end{array}\right.
$$

where $\sigma$ is the Stefan-Boltzmann constant, $\varepsilon_{a}$ is the emissivity of the pavement surface, $T_{e}$ is the temperature of the environment, $T_{a}$ is the temperature of the pavement surface, and $h_{a}$ is the mean convective heat transfer coefficient for the pavement-air interface. The value of $h_{a}$ can be calculated as $h_{c}=6.1+3.7 \cdot v_{w}$, where $v_{w}$ is the velocity of the wind [16. In this work the velocity of the wind crossing the prototype is considered as constant and equal to zero, as the experiments were performed in a laboratory.

It is relevant to report that the air speed influences the value of the efficiency shown in Eq. 3, as the mass flow $\dot{m}$ is calculated as:

$$
\dot{m}=\rho \cdot v \cdot A
$$

where $\rho$ is the density of air at the chimney outlet, $v$ is the air speed, and $A$ is the chimney cross section.

As shown in Fig. 6, the efficiency varies quite widely for the configurations that 


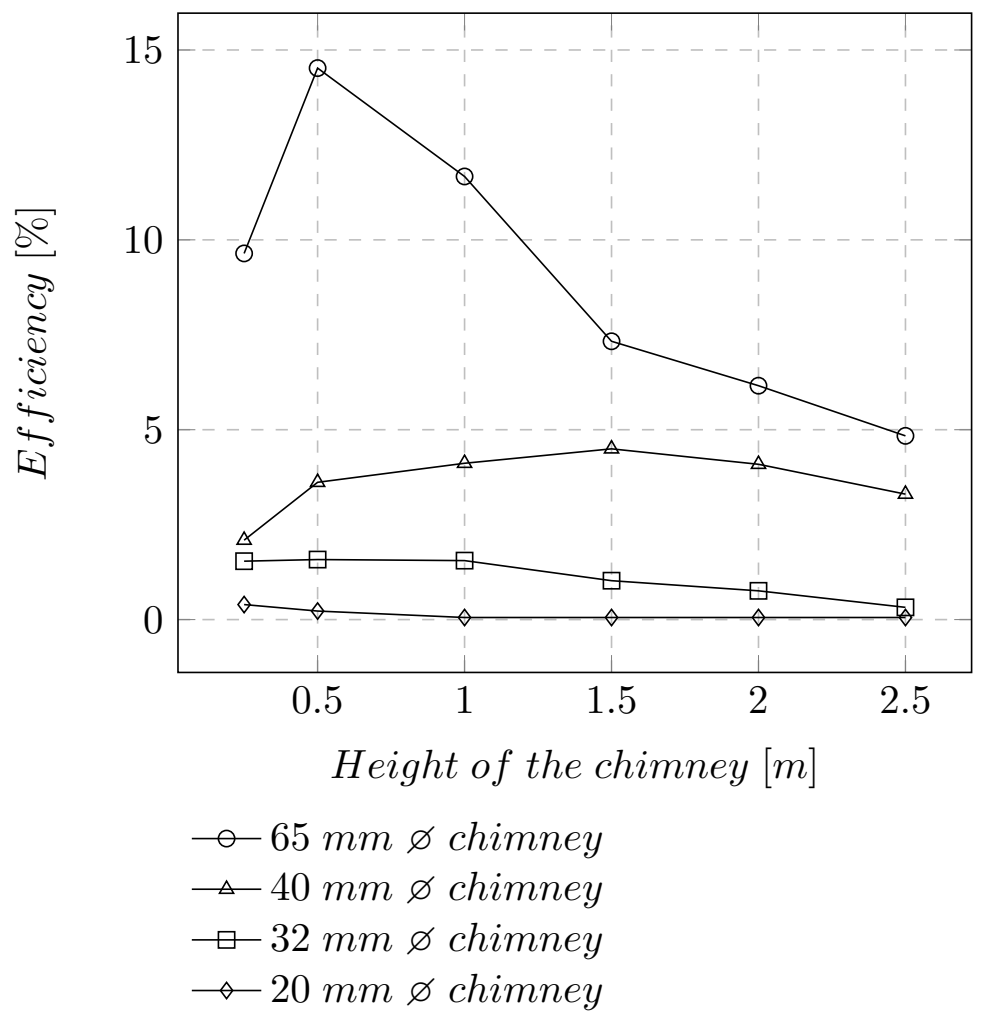

Figure 6: Energy efficiency of the energy harvesting process.

were tested, reaching its maximum value in the case of a $0.5 \mathrm{~m}$ long chimney with an internal diameter of $65 \mathrm{~mm}$.

The definition of efficiency formulated in Eq. 3 is focused on the energy harvesting potential, but other definitions based on different points of view may be considered. For example, in the case of the reduction of the UHI effect, a definition based on the surface temperature could be developed:

$$
\eta_{U H I}=\frac{T 3_{N H}-T 3}{T 3_{N H}}
$$

where $T 3_{N H}$ is the temperature of the pavement surface with no energy harvesting and $T 3$ is the temperature of the surface found in the laboratory experiments. The same kind of efficiency can be calculated with the temperature at the bottom layer of the prototype, $T 2_{N H}$ and $T 2$. The reference tempera- 
tures called $T_{N H}$ were determined by performing a full test with all the pipes obstructed, thus, not allowing air to remove heat from the pavement surface. The values of $T 3_{N H}$ and $T 2_{N H}$ are then $78.81^{\circ} \mathrm{C}$ and $65.16^{\circ} \mathrm{C}$ respectively. Let us add that the temperature in the bottom layer may show values that differ from those found in the field, because the insulation that covers all sides of the prototype prevents the heat flux from moving to other underlying layers. The results so obtained are gathered in Fig. 7f the graphs show that the experimental setup with the chimney having a diameter of $65 \mathrm{~mm}$ is the one that offers the best performance in terms of temperature reduction in both layers when a realistic chimney height $(>1 \mathrm{~m})$ is considered.

\subsection{Additional considerations}

Additional tests were performed in order to evaluate, at least qualitatively, the sensitivity of the system to variables that could not be considered for a real parametric studies, i.e. the number of pipes in the aggregate layer and the air box volume. The results obtained from these tests are shown in Table 2 .

\begin{tabular}{llllll} 
Experimental setup & $\mathrm{T} 1\left[{ }^{\circ} \mathrm{C}\right]$ & $\mathrm{T} 2\left[{ }^{\circ} \mathrm{C}\right]$ & $\mathrm{T} 3\left[{ }^{\circ} \mathrm{C}\right]$ & $\mathrm{T} 4\left[{ }^{\circ} \mathrm{C}\right]$ & Air speed $[\mathrm{m} / \mathrm{s}]$ \\
\hline Top pipes blocked & 74.58 & 44.26 & 74.70 & 37.25 & 0.34 \\
Bottom pipes blocked & 69.93 & 46.01 & 71.47 & 39.13 & 0.36 \\
Mixed pipes blocked & 72.16 & 45.71 & 72.63 & 36.87 & 0.36 \\
$50 \%$ air box volume & 69.84 & 39.65 & 71.35 & 38.40 & 0.36 \\
Standard configuration & 71.39 & 41.90 & 72.46 & 40.50 & 0.51 \\
\hline
\end{tabular}

Table 2: Modified experimental setups for qualitative analysis (1 m high chimney, $65 \mathrm{~mm} \varnothing)$.

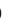

It is interesting to note that the reduction of the air box volume and the obstruction of the bottom layer of pipes have a very similar effect on all the parameters under investigation.

Moreover, by blocking the top layer of pipes, the temperature T3 is higher than by blocking the bottom layer of pipes, thus, implying that the reduction of the pavement surface temperature is achieved more effectively via the upper set of pipes.

Finally, if one compares the results of the best performing modified setups in 


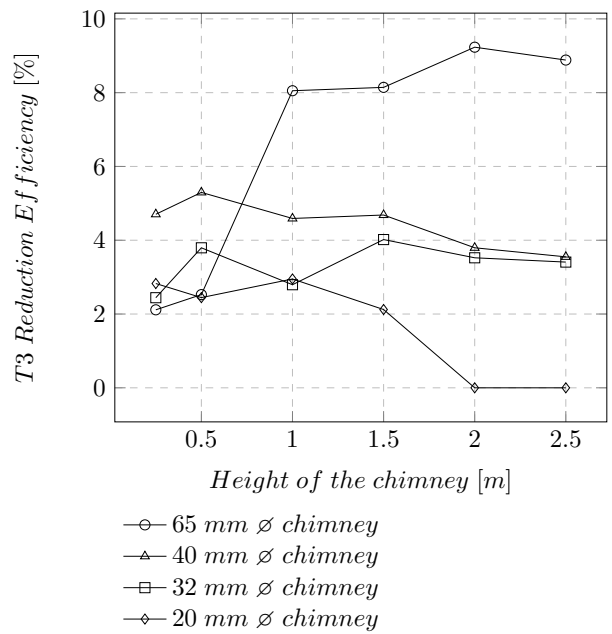

(a) Reduction of T3.

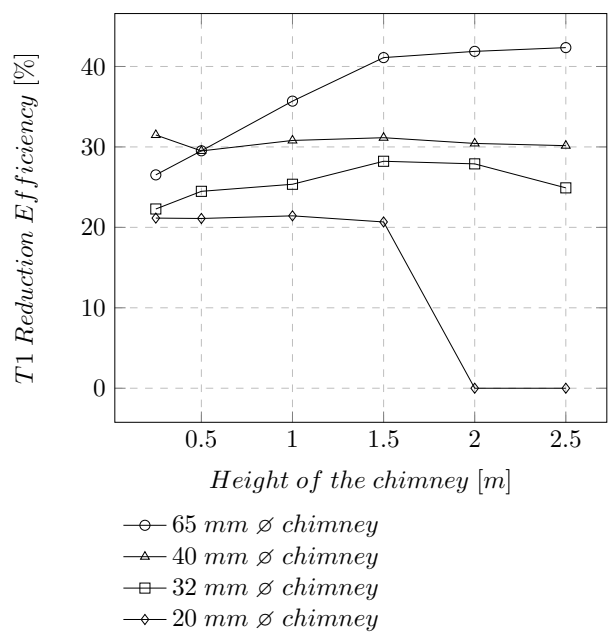

(b) Reduction of T1.

Figure 7: Temperature reduction efficiency.

258

259

260

261

terms of temperatures and/or air speed with those obtained in standard conditions with a $1 \mathrm{~m}$ high chimney, it can be seen that the overall performance 260 is quite similar in terms of temperatures, while the air speed is considerably higher in the standard configuration. 


\section{Mathematical model}

The results show that the behaviour of the system is influenced by thermofluid dynamics. However, as an approximation, a preliminary model of the system can be developed based on simple thermodynamic concepts [5].

This model describes the system with 1D equations, because heat transfer in the horizontal direction is negligible due to the use of insulated walls. The equations used consist of heat balances made on the surfaces highlighted in Fig. 8 and they are developed as if the system was made of 13 separated identical sections each consisting of an asphalt layer, an aggregate layer, and one pipe.

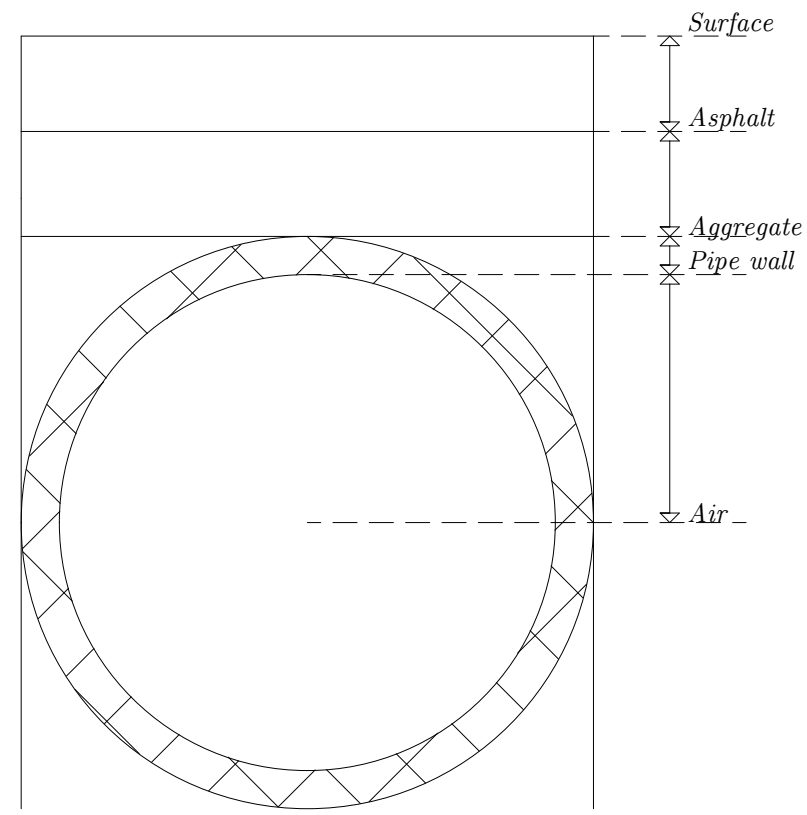

Figure 8: Layers and control surfaces for the 1D thermodynamic model.

As a simplification, for this approximated model let us consider a $d x$ wide portion of the domain shown in Fig. 8, thus, allowing the analysis of the pipe wall as a horizontal slab.

Based on this simplification, Fourier's law can be applied on all the surfaces shown in Fig. 8, considering that the heat flux entering the domain can be found with Eq. 4 in the hypothesis of no heat losses and no heat accumulation: 


$$
\left\{\begin{array}{l}
q_{\max }=k_{a} \cdot\left(T_{a}-T_{g}\right) / L_{a} \\
k_{a} \cdot\left(T_{a}-T_{g}\right) / L_{a}=k_{g} \cdot\left(T_{g}-T_{p}^{e x t}\right) / L_{g} \\
k_{g} \cdot\left(T_{g}-T_{p}^{e x t}\right) / L_{g}=k_{p} \cdot\left(T_{p}^{e x t}-T_{p}^{i n t}\right) / L_{p}
\end{array}\right.
$$

where the subscript $a$ describes the asphalt layer, $g$ describes the aggregate, and $p$ describes the steel pipes. Moreover, $k$ and $L$ are the thermal conductivity and the thickness of the layer indicated by the subscript.

If the heat transfer coefficient inside the pipes is known, the temperature of the air flowing in the pipes may be easily calculated with the following equation that models convective heat transfer in a pipe:

$$
q_{\text {max }}=h_{p-a i r} \cdot A_{p} \cdot\left(T_{p}^{i n t}-T_{a v, a i r}\right)
$$

where $h_{p-a i r}$ is the convective coefficient mentioned above, $A_{p}$ is the internal surface of the pipes, and $T_{a v, a i r}$ is the average temperature of the operating fluid. However, it is not possible to calculate $T_{a v}$,air with Eq. 9. because in the experimental setup that was used no data is available about the air speed in the pipes, thus, it is not possible to calculate the value of $h_{p-a i r}$.

Since the air speed in the pipes is low, the equation of conduction can be used as an approximation to describe convective heat transfer through air in the pipe in order to calculate $T_{a v, a i r}$ :

$$
k_{p} \cdot\left(T_{p}^{e x t}-T_{p}^{i n t}\right) / L_{p}=k_{a i r} \cdot\left(T_{p}^{i n t}-T_{a v, a i r}\right) / L_{a i r}
$$

where $L_{a i r}$ is equal to the internal radius of a pipe. This hypothesis has to be validated, but no data is available about the temperature in the pipes: for this reason, an additional set of equations can be used to estimate the temperature of air in the chimney (which is measured) based on the previous hypotheses and on the additional assumption that there are no heat losses in the air box and along the chimney [5]. In order to calculate the temperature in the chimney the first step is the calculation of the value of $T_{a v, a i r}$ for all the pipes with Eq. 10, considering that they are placed at two different levels, thus, the correct $L_{g}$ 
has to be used. For this reason, a distinction between the top layer (subscript $t$ ) and the bottom layer (subscript $b$ ) is used from now on. Of course, since the model is simplified, only two temperatures are calculated, i.e. $T_{b}$ for the pipes in the bottom layer and $T_{t}$ for the pipes in the top layer.

Since the air box collects the air coming from all the pipes, its equilibrium temperature can be calculated based on the principle of energy conservation considering that the air in the 13 pipes ( 6 from the top layer, 7 from the bottom layer) is mixed adiabatically:

$$
m_{b}^{t o t} \cdot c_{p, a i r} \cdot\left(T_{e q}-T_{b}\right)=m_{t}^{t o t} \cdot c_{p, a i r} \cdot\left(T_{e q}-T_{t}\right)
$$

where $m_{b}^{\text {tot }}$ is the total mass of air in the bottom layer of pipes, $m_{t}^{\text {tot }}$ is the total mass of air in the top layer of pipes, $T_{e q}$ is the equilibrium temperature in the air box, and $c_{p, a i r}$ is the specific heat capacity of air. In the temperature and pressure range under analysis the value of $c_{p, \text { air }}$ is considered constant.

The mass of air in each pipe can be found as $m_{\text {air }}^{\text {pipe }}=\rho_{\text {air }} \cdot V_{\text {air }}$, where $\rho_{\text {air }}$ is calculated with the ideal gas law at the relevant $T_{a v, a i r}$ and $V_{a i r}$ is the volume of a pipe. Therefore, the equilibrium temperature is calculated as:

$$
T_{e q}=\frac{7 \cdot m_{b}^{p i p e} \cdot T_{b}-6 \cdot m_{t}^{p i p e} \cdot T_{t}}{7 \cdot m_{b}^{p i p e}-6 \cdot m_{t}^{p i p e}}
$$

Under the assumption of no heat losses, one may conclude that the temperature at the chimney outlet is equal to the equilibrium temperature in the air box. The results obtained following this procedure are shown in Fig. 9, while the constants used in the computation of $T_{e q}$ and in the previous calculations are gathered in Table 3 .

The data shown in Fig. 9 clearly confirms that the model is preliminary, since the relative error is very high in two of the analysed layouts. However, the results are acceptable as an approximation for chimney diameters above $40 \mathrm{~mm}$ if a rough estimation of the chimney temperature is needed. Moreover, it is possible to conclude that for diameter below $40 \mathrm{~mm}$ fluid dynamics plays a more important role, as the simply thermodynamic model is unable to fit the experimental data. This result is useful to confirm that a more advanced analysis needs to be 
performed to study in detail the system under investigation, for example using computational fluid dynamics (CFD simulations). This kind of further analysis would also provide the designer with useful information concerning the air speed at the outlet.

Even if the temperature in the chimney cannot be estimated in a simple way in all cases due to the effects of fluid dynamics, the temperatures in the other positions of the domain, i.e. T1 and T2, can be calculated with the 1D model with an error ranging between $0.004 \%$ and $8 \%$ (without taking into account possible errors due to the equipment used for measurements).

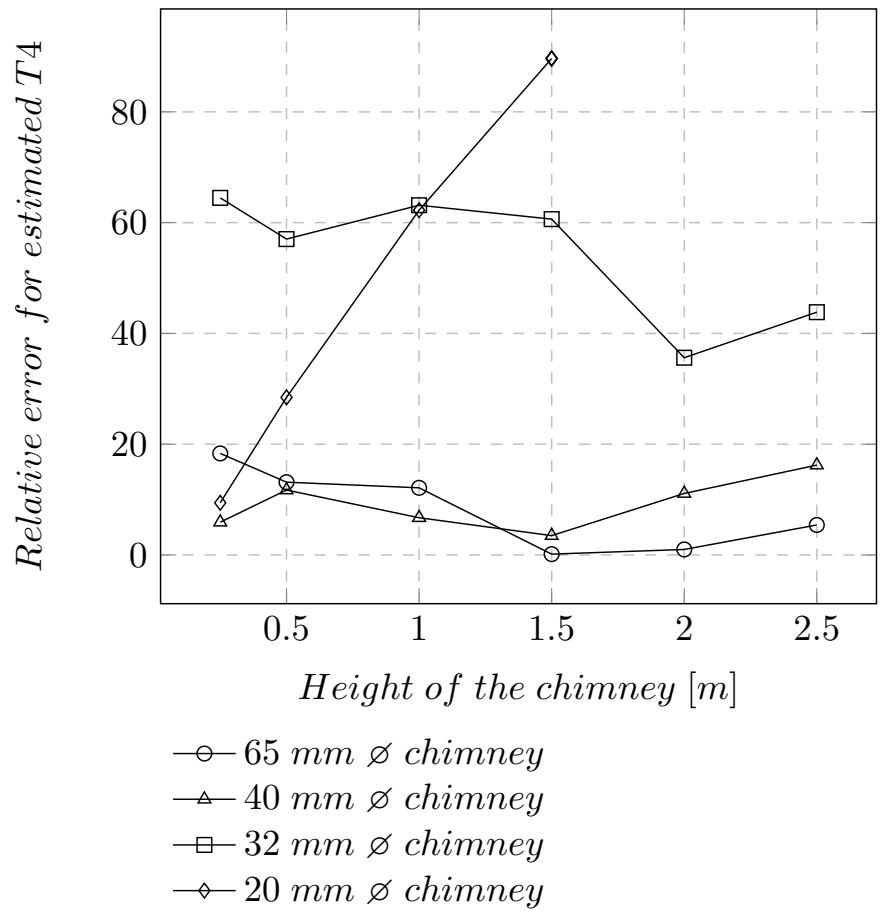

Figure 9: Relative error for the chimney temperature found with the preliminary model.

\section{Conclusions}

In this paper a parametric analysis of the performance of an energy harvesting pavement was presented and discussed. The following conclusions can be 


\begin{tabular}{llll} 
Symbol & Value & Unit & Source \\
\hline$k_{a}$ & 1.2 & $\mathrm{~W} /(\mathrm{m} \mathrm{K})$ & {$[17]$} \\
$k_{g}$ & 0.55 & $\mathrm{~W} /(\mathrm{m} \mathrm{K})$ & {$[18]$} \\
$k_{p}$ & $\sim 15\left(\sim 50^{\circ} \mathrm{C}\right)$ & $\mathrm{W} /(\mathrm{m} \mathrm{K})$ & {$[19]$} \\
$k_{\text {air }}$ & $0.02785\left(\sim 50^{\circ} \mathrm{C}\right)$ & $\mathrm{W} /(\mathrm{m} \mathrm{K})$ & {$[20]$} \\
$L_{a}$ & 0.05 & $\mathrm{~m}$ & \\
$L_{\text {top layer }}$ & 0.015 & $\mathrm{~m}$ & \\
$L_{\text {bottom layer }}$ & 0.115 & $\mathrm{~m}$ & \\
$L_{p}$ & 0.001 & $\mathrm{~m}$ & \\
$L_{a i r}$ & 0.015 & $\mathrm{~m}$ & \\
$A_{a}$ & 0.0141 & $\mathrm{~m}{ }^{2}$ & \\
$\varepsilon_{a}$ & 0.823 & $/ /$ & {$[21]$} \\
$\alpha_{a}$ & 0.9 & $/ /$ & {$[3]$} \\
$h_{a}$ & 6.1 & $\mathrm{~W} /\left(\mathrm{m}^{2} \mathrm{~K}\right)$ & {$[16]$} \\
$q_{i}$ & 1300 & $\mathrm{~W} / \mathrm{m}^{2}$ & \\
\hline
\end{tabular}

Table 3: Constants used for the model developed.

drawn:

- Air-driven energy harvesting from pavements is feasible.

- The chimney height and the chimney diameter are equally important for the final performance of the system, thus, an optimal combination between them needs to be used.

- The energy harvesting process needs to be described with the use of fluid dynamics, since the Reynolds number of the fluid flow is sensitive to temperature variations.

- The energy efficiency of harvesting pavements can get up to almost $15 \%$. However, this implies a not optimal air speed, thus, the aim of the harvesting process needs to be clear to the designer.

- The air speed at the outlet is controlled by the height and diameter of the chimney and it only reached $0.58 \mathrm{~m} / \mathrm{s}$ with the prototype that was tested. Therefore, this small-sized prototype is not likely to be suitable for electricity production purposes. 
- The system that was developed offers the possibility to control effectively the temperature of a pavement, thus, improving its durability.

\section{Acknowledgments}

The authors thank the University of Nottingham for the financial support provided for the Ph.D. of Andrea Chiarelli. 


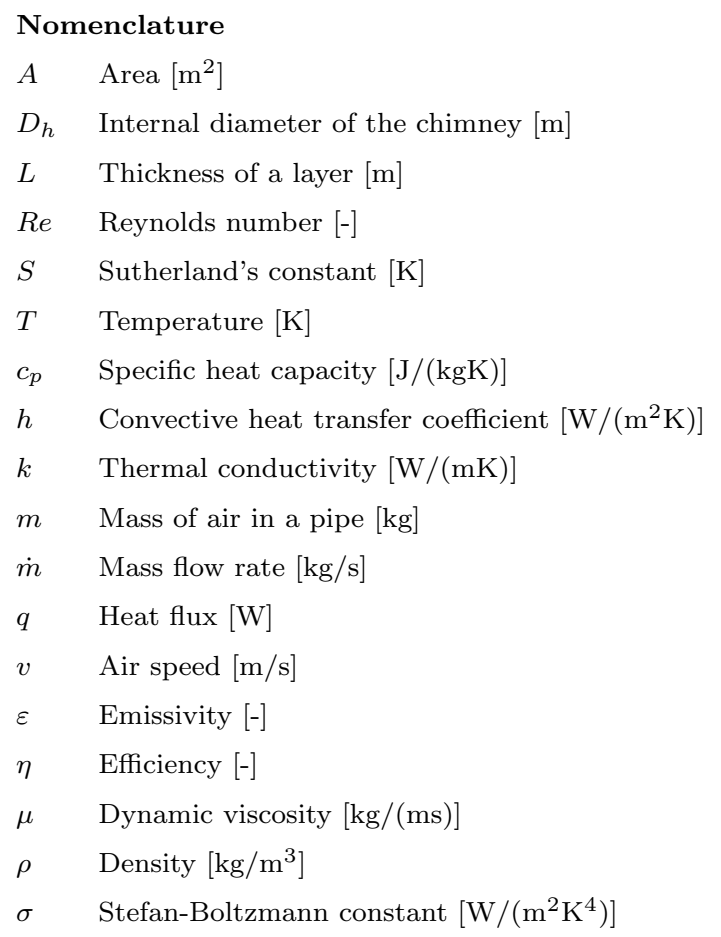

\section{References}

[1] P. Pascual-Muñoz, D. Castro-Fresno, P. Serrano-Bravo, A. AlonsoEstbanez, Thermal and hydraulic analysis of multilayered asphalt pavements as active solar collectors, Applied Energy 111 (2013) 324-332. doi:10.1016/j.apenergy.2013.05.013.

[2] A. K. Apeagyei, E. V. Dave, W. G. Buttlar, Effect of cooling rate on thermal cracking of asphalt concrete pavements, Journal of the Association of Asphalt Paving Technologists 77 (2008) 709-738.

[3] V. Bobes-Jesus, P. Pascual-Muñoz, D. Castro-Fresno, J. RodriguezHernandez, Asphalt solar collectors: A literature review, Applied Energy 102 (2013) 962-970. doi:10.1016/j.apenergy.2012.08.050

[4] A. García, M. Partl, How to transform an asphalt concrete pavement into 
371 a solar turbine, Applied Energy 119 (2014) 431-437. doi:10.1016/j.

372 apenergy.2014.01.006.

[5] A. Chiarelli, A. Dawson, A. García, Analysis of the performance of an airpowered energy harvesting pavement - in press, Transportation Research Record: Journal of the Transportation Research Board.

n [6] J. W. Lund, Pavement snow melting, http://geoheat.oit.edu/ bulletin/bull21-2/art4.pdf, accessed Jul. 22, 2014 (2000).

[7] R. Sarachitti, C. Chotetanorm, C. Lertsatitthanakorn, M. Rungsiyopas, Thermal performance analysis and economic evaluation of roof-integrated solar concrete collector, Energy and Buildings 43 (2011) 1403-1408. doi: 10.1016/j.enbuild.2011.01.020.

[8] R. H. Sedgwick, M. Patrick, The use of a ground solar collector for swimming pool heating, in: Solar World Forum. In: Proceedings of ISES, 1992, pp. $632-636$.

[9] R. Mallick, S. Bhowmick, M. Hulen, Capturing solar energy from asphalt pavements, http://users.wpi.edu/ rajib/Pavement\% 20Energy-ISAP-August\%202008.pdf, accessed Jan. 07, 2015.

[10] K. Avila, D. Moxey, A. de Lozar, M. Avila, D. Barkley, B. Hof, The onset of turbulence in pipe flow, Science 333 (2011) 192-196. doi:10.1126/ science.1203223.

[11] R. K. Singh, M. R. Ahmed, Blade design and performance testing of a small wind turbine rotor for low wind speed applications, Renewable Energy 50 (2013) 812-819. doi:10.1016/j.renene.2012.08.021.

[12] M. Dongellini, C. Naldi, G. L. Morini, Seasonal performance evaluation of electric air-to-water heat pump systems, Applied Thermal Engineering (2015) doi:10.1016/j.applthermaleng.2015.03.026. 
[13] A. Allen, D. Milenic, P. Sikora, Shallow gravel aquifers and the urban heat island effect: a source of low enthalpy geothermal energy, Geothermics 32 (2003) 569-579. doi:10.1016/S0375-6505(03)00063-4.

[14] E. J. Gago, J. Roldan, R. Pacheco-Torres, J.Ordonez, The city and urban heat islands: A review of strategies to mitigate adverse effects, Renewable and Sustainable Energy Reviews 25 (2013) 749-758. doi:10.1016/j.rser. 2013.05 .057

[15] R. B. Mallick, B. Chen, S. Bhowmick, Reduction of urban heat island effect through harvest of heat energy from asphalt pavements, http://heatisland2009.lbl.gov/docs/211420-mallick-doc.pdf accessed Apr. 28, 2015.

[16] H. Li, J. Harvey, T. Holland, M. Kayhanian, The use of reflective and permeable pavements as a potential practice for heat island mitigation and stormwater management, Environmental Research Letters 8 (2013) 1-14. doi: $10.1088 / 1748-9326 / 8 / 1 / 015023$

[17] J. J. Stempihar, T. Pourshams-Manzouri, K. E. Kaloush, M. C. Rodezno, Porous asphalt pavement temperature effects for urban heat island analysis, Transportation Research Record: Journal of the Transportation Research Board 2293/2012 Asphalt Materials and Mixtures (2012) 123-130. doi: 10.3141/2293-15.

[18] N. I. Kömle, H. Bing, W. J. Feng, R. Wawrzaszek, E. S. Hütter, P. He, W. Marczewski, B. Dabrowski, K. Schröer, T. Spohn, Thermal conductivity measurements of road construction materials in frozen and unfrozen state, Acta Geotechnica 2 (2007) 127-138. doi:10.1007/s11440-007-0032-1.

[19] M. J. Assael, K. Gialou, K. Kakosimos, I. Metaxa, Thermal conductivity of reference solid materials, International Journal of Thermophysics 25 (2004) 397-408. doi:10.1023/B:IJOT.0000028477.74595.d5. 
[20] W. M. Haynes, Handbook of chemistry and physics, CRC Press, Taylor \& Francis Group, 2012.

[21] A. Hassn, M. Aboufoul, Y. Wu, A. Dawson, A. García, Effect of air voids content on the heat transfer properties of asphalt mixture - in review, Construction and Building Materials. 
${ }_{429}$ Appendix A. Temperatures measured in the tests performed

\begin{tabular}{|c|c|c|c|c|}
\hline \multicolumn{5}{|c|}{ Chimney $\varnothing 65 \mathrm{~mm}$} \\
\hline Height $[\mathrm{m}]$ & $\mathrm{T} 1\left[{ }^{\circ} \mathrm{C}\right]$ & $\mathrm{T} 2\left[{ }^{\circ} \mathrm{C}\right]$ & $\mathrm{T} 3\left[{ }^{\circ} \mathrm{C}\right]$ & $\mathrm{T} 4\left[\begin{array}{ll}{ }^{\circ} \mathrm{C}\end{array}\right]$ \\
\hline 0.25 & 76.08 & 47.88 & 77.14 & 48.43 \\
\hline 0.50 & 75.70 & 45.93 & 76.82 & 45.06 \\
\hline 1.00 & 71.39 & 41.90 & 72.46 & 40.50 \\
\hline 1.50 & 69.93 & 38.38 & 72.39 & 34.68 \\
\hline 2.00 & 68.63 & 37.87 & 71.53 & 33.84 \\
\hline 2.50 & 68.80 & 37.57 & 71.81 & 32.55 \\
\hline \multicolumn{5}{|c|}{ Chimney $\varnothing 40 \mathrm{~mm}$} \\
\hline Height $[\mathrm{m}]$ & $\mathrm{T} 1\left[^{o} \mathrm{C}\right]$ & $\mathrm{T} 2\left[^{\circ} \mathrm{C}\right]$ & $\mathrm{T} 3\left[^{\circ} \mathrm{C}\right]$ & $\mathrm{T} 4\left[^{\circ} \mathrm{C}\right]$ \\
\hline 0.25 & 73.70 & 44.65 & 75.10 & 39.32 \\
\hline 0.50 & 73.31 & 45.94 & 74.63 & 41.63 \\
\hline 1.00 & 73.80 & 45.09 & 75.19 & 39.34 \\
\hline 1.50 & 73.78 & 44.86 & 75.12 & 37.89 \\
\hline 2.00 & 74.41 & 45.33 & 75.82 & 33.74 \\
\hline 2.50 & 74.66 & 45.51 & 76.01 & 32.28 \\
\hline \multicolumn{5}{|c|}{ Chimney $\varnothing 32 \mathrm{~mm}$} \\
\hline Height $[\mathrm{m}]$ & $\mathrm{T} 1\left[{ }^{\circ} \mathrm{C}\right]$ & $\mathrm{T} 2\left[{ }^{\circ} \mathrm{C}\right]$ & $\mathrm{T} 3\left[{ }^{\circ} \mathrm{C}\right]$ & $\mathrm{T} 4\left[^{\circ} \mathrm{C}\right]$ \\
\hline 0.25 & 76.49 & 50.64 & 76.88 & 23.64 \\
\hline 0.50 & 75.05 & 49.21 & 75.82 & 24.24 \\
\hline 1.00 & 75.90 & 48.64 & 76.61 & 23.52 \\
\hline 1.50 & 74.51 & 46.77 & 75.64 & 23.38 \\
\hline 2.00 & 75.00 & 46.98 & 76.03 & 27.78 \\
\hline 2.50 & 75.14 & 48.93 & 76.12 & 27.06 \\
\hline \multicolumn{5}{|c|}{ Chimney $\varnothing 20$ mm } \\
\hline Height $[\mathrm{m}]$ & $\mathrm{T} 1\left[^{o} \mathrm{C}\right]$ & $\mathrm{T} 2\left[^{o} \mathrm{C}\right]$ & $\mathrm{T} 3\left[{ }^{o} \mathrm{C}\right]$ & $\mathrm{T} 4\left[^{o} \mathrm{C}\right]$ \\
\hline 0.25 & 76.10 & 51.38 & 76.58 & 35.37 \\
\hline 0.50 & 76.54 & 51.41 & 76.88 & 30.35 \\
\hline 1.00 & 76.16 & 51.19 & 76.48 & 23.83 \\
\hline 1.50 & 76.58 & 51.69 & 77.14 & 20.59 \\
\hline 2.00 & $\mathrm{n} / \mathrm{a}$ & $\mathrm{n} / \mathrm{a}$ & $\mathrm{n} / \mathrm{a}$ & $\mathrm{n} / \mathrm{a}$ \\
\hline 2.50 & $\mathrm{n} / \mathrm{a}$ & $\mathrm{n} / \mathrm{a}$ & $\mathrm{n} / \mathrm{a}$ & $\mathrm{n} / \mathrm{a}$ \\
\hline
\end{tabular}

